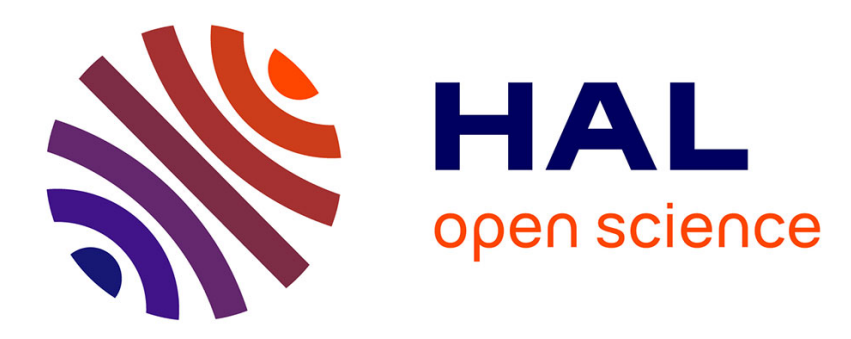

\title{
Residual radioactivity of silicon doped by transmutation
}

\author{
V.K. Agrawal, F. Benière
}

\section{To cite this version:}

V.K. Agrawal, F. Benière. Residual radioactivity of silicon doped by transmutation. Journal de Physique Lettres, 1979, 40 (3), pp.49-51. 10.1051/jphyslet:0197900400304900 . jpa-00231567

\section{HAL Id: jpa-00231567 https://hal.science/jpa-00231567}

Submitted on 1 Jan 1979

HAL is a multi-disciplinary open access archive for the deposit and dissemination of scientific research documents, whether they are published or not. The documents may come from teaching and research institutions in France or abroad, or from public or private research centers.
L'archive ouverte pluridisciplinaire HAL, est destinée au dépôt et à la diffusion de documents scientifiques de niveau recherche, publiés ou non, émanant des établissements d'enseignement et de recherche français ou étrangers, des laboratoires publics ou privés. 


\title{
Residual radioactivity of silicon doped by transmutation
}

\author{
V. K. Agrawal (*) and F. Benière \\ Laboratoịre de Physique des Matériaux, Institut Universitaire de Technologie, 22302 Lannion, France.
}

(Reçu le 13 octobre 1978, révisé le $1^{\text {er }}$ décembre 1978, accepté le 5 décembre 1978)

\begin{abstract}
Résumé. - Nous avons étudié la double rêaction nucléaire (Si-30 $\rightarrow$ Si-31 $\rightarrow$ P-31 $\rightarrow$ P-32) qui produit l'isotope radioactif P-32 par irradiation du silicium par des neutrons thermiques. Une équation a été établie afin de relier la radioactivité de $\mathrm{P}-32$ à la section efficace de capture de P-31. La section efficace ainsi déterminée à partir des mesures de la radioactivité de P-32 est en bon accord avec la valeur classique. Il est ainsi possible de prédire la radioactivité du silicium dopé par transmutation nucléaire pour toute dose et à tout moment. Une équation a également été établie pour relier la radioactivité de P-32 au nombre de donneurs créés.
\end{abstract}

\begin{abstract}
The complex nuclear reaction (Si-30 $\rightarrow$ Si-31 $\rightarrow$ P-31 $\rightarrow$ P-32) leading to the formation of radioactive P-32 by irradiation of silicon with thermal neutrons, has been studied. An expression has been derived to correlate the activity of P-32 with the neutron cross-section of P-31. The neutron cross-section thus computed from the experimentally measured activity of P-32 is in good agreement with the classical value. It is then possible to predict the radioactivity of silicon doped by nuclear transmutation for any neutron dose at any time. An expression has also been derived to correlate the activity of P-32 to the number of donors created.
\end{abstract}

1. Introduction. - Neutron transmutation doping using the following reaction :

$$
{ }_{14}^{30} \mathrm{Si}+\mathrm{n} \rightarrow{ }_{14}^{31} \mathrm{Si} \rightarrow{ }_{15}^{31} \mathrm{P}+\beta^{-}
$$

is being used to convert ingots of high resistivity silicon into striation free, precisely doped n-type material $[1,2]$. This neutron transmutation doped material is being successfully used in the production of high voltage thyristors and diodes [3, 4]. Recently, a comparatively large neutron flux

$$
\left(\sim 10^{19} \text { neutrons } . \mathrm{cm}^{-2}\right)
$$

has been employed to produce precisely and homogeneously doped n-type epitaxial layers [5].

In an earlier publication [6], it was shown that the phosphorus concentration thus produced by neutron irradiation is uniform even at a microscopic level $(500 \AA)$. The neutron irradiation not only produces phosphorus but also activates the background impurities present in silicon. This was utilized to study the distribution of gold in silicon from the surface into the bulk of the crystal which was found to be non-

(*) Permanent address : Physics Department, University of Allahabad, Allahabad 211 002, India. uniform. The neutron irradiation also gives rise to another nuclear transmutation :

$$
{ }_{15}^{31} \mathrm{P}+\mathrm{n} \rightarrow{ }_{15}^{32} \mathrm{P} \rightarrow{ }_{16}^{32} \mathrm{~S}+\beta^{-} .
$$

The aim of the present work is to study this secondary transmutation. The half-life time of $\mathrm{P}-32$ is 14.3 days as compared to $2.62 \mathrm{~h}$ of Si-31. Thus this can be studied as residual radioactivity of neutron irradiated silicon samples. We shall first derive the expression for the radioactivity of $\mathrm{P}-32$ to evaluate the neutron cross-section. We shall then give the numerical expression relating the residual beta-radioactivity of the neutron doped silicon to the number of carriers produced.

2. Theory : radioactivity of $\mathbf{P}-32$ atoms. - Several processes occur inside the reactor :

a) the production of $\mathrm{Si}-31$ from $\mathrm{Si}-30, b)$ the transmutation of $\mathrm{Si}-31$ into $\mathrm{P}-31, c)$ the activation of P-31 to P-32 and $d$ ) the decay of P-32 to S-32. Besides these reactions, radioactivation of impurities and activation of Si-28 and $\mathrm{Si}-29$ also take place but are not of interest in the present case.

The total activity, $A$, per $\mathrm{g}$ of silicon in $4 \pi$ solid 
angle due to $\mathrm{Si}-31$ at the instant the sample is removed from the reactor is conveniently given by [6] :

$$
\begin{aligned}
A=\frac{36 \times \sigma \times J}{M} \times[1- & \left.\exp \left(-\lambda t_{1}\right)\right] \times \\
& \times A I \times P M \text { cpm per } \mathrm{g}
\end{aligned}
$$

where

$\sigma=$ neutron cross-section of $\mathrm{Si}-30=0.102$ barn,

$J=$ neutron flux in neutrons $/ \mathrm{cm}^{2} / \mathrm{s}$,

$\lambda=$ radioactive constant of $\mathrm{Si}-31=7.35 \times 10^{-5} \mathrm{~s}^{-1}$, $A I=$ isotopic abundance of $\mathrm{Si}-30(=0.030)$,

$P M=$ the mode of decay (=1, for this case),

$M=$ atomic mass of silicon,

$t_{1}=$ time of irradiation.

Time $t$ is taken as zero at the instant samples are removed from the pile. The activity as given by the counter at any time $t_{2}$ in counts per minute per gram of silicon is

$$
A_{\text {counter }}=A \times R C \times \exp \left(-\lambda t_{2}\right) \mathrm{cpm} \text { per } \mathrm{g}
$$

where $R C$ stands for the efficiency of the counter.

Because of the short half-life time of Si-31, this radioactivity $A$ quickly tends to zero. On the contrary, the radioactivity of P-32 decays much more slowly and after a few days it is the principal contributor to the radioactivity. Let $A^{\prime}$ denote this radioactivity that we are now going to relate to the neutron dose and finally, the number of carriers.

To a good approximation, the number of P-31 atoms which appear is equal to the number of $\mathrm{Si}-31$ atoms which disappear. A few hours after putting the samples in the nuclear reactor, one has

$$
1-\exp \left(-\lambda t_{1}\right) \simeq 1 \text {. }
$$

Then, the number of P-31 atoms produced between time $t$ and $t+\mathrm{d} t$ is :

$$
\mathrm{d} N=\frac{36 \times \sigma \times J}{M} \times A I \times \mathrm{d} t
$$

having the infinitesimal mass (per gram of silicon) :

$$
\mathrm{d} m^{\prime}=\frac{36 \times \sigma \times J}{M} \times A I \times \frac{M^{\prime}}{N_{\mathrm{A}}} \mathrm{d} t
$$

where $M^{\prime}$ denotes the atomic mass of P-31 and $N_{\mathrm{A}}$ the Avogadro's number.

These $\mathrm{d} N$ atoms are subject to the neutron flux during the remaining time $=t_{1}-t$ (Fig. 1). These will give the infinitesimal contribution to the radioactivity of P-32 at the time $t_{2}$ :

$$
\begin{aligned}
\mathrm{d} A^{\prime}= & \frac{36 \times \sigma^{\prime} \times J}{M^{\prime}} \times \\
& \times \frac{\left[1-\exp \left\{-\lambda^{\prime}\left(t_{1}-t\right)\right\}\right]}{\exp \left(\lambda^{\prime} t_{2}\right)} \mathrm{d} m^{\prime} \times R C
\end{aligned}
$$

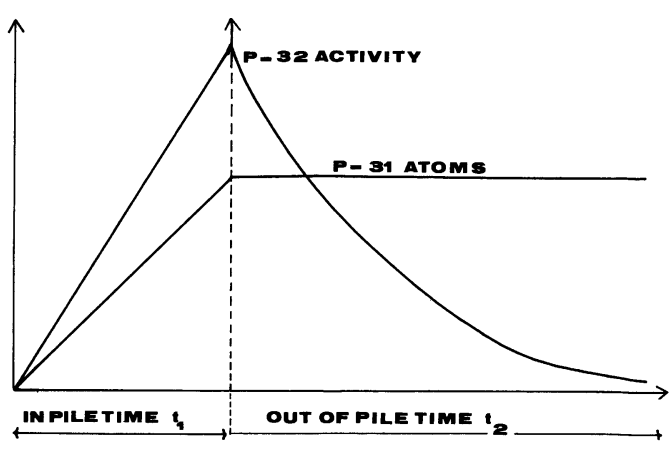

Fig. 1. - Schematic variation in the activity of P-32 with time inside and outside the reactor.

where $\sigma^{\prime}$ is the neutron cross-section of P-31 in barn $P M$ and $A I$ are unity for P-31 activation. Substitution of $\mathrm{d} m^{\prime}$ from (6) into (7) gives

$$
\begin{aligned}
\mathrm{d} A^{\prime}=\frac{(36 J)^{2} \sigma \sigma^{\prime}}{N_{\mathrm{A}} \cdot M} \times \frac{\left[1-\exp \left\{-\lambda^{\prime}\left(t_{1}-t\right)\right\}\right]}{\exp \left(\lambda^{\prime} t_{2}\right)} \times \\
\times A I \times R C \times \mathrm{d} t
\end{aligned}
$$

The total activity due to all P-32 atoms produced in time $t_{1}$ is thus obtained by integrating between $t=0$ to $t=t_{1}$ as

$$
A^{\prime}=\frac{(36 J)^{2} \sigma \sigma^{\prime}}{N_{\mathrm{A}} \cdot M} \times \frac{\left[t_{1}-\frac{1}{\lambda^{\prime}}\left\{1-\exp \left(-\lambda^{\prime} t_{1}\right)\right\}\right]}{\exp \left(\lambda^{\prime} t_{2}\right)} \times
$$

3. Experimental results. - Hyper pure silicon crystals supplied by Wacker were used. They are float-zone, dislocation free, grown in the 1-0-0 orientation, p-type containing boron, the concentration of boron ranging from $10^{13}$ up to $10^{16}$ atoms $/ \mathrm{cm}^{3}$. The neutron activation analysis confirms the high purity if one excepts the gold which is

$$
3 \times 10^{13} \text { atoms } / \mathrm{cm}^{3} \text {. }
$$

The samples, carefully washed and cleaned, were normally irradiated in a thermal neutron flux of $3.5 \times 10^{13}$ neutrons $\mathrm{cm}^{-2} \mathrm{~s}^{-1}$ for a period of 7 days. Longer irradiation time helps to increase the measurable radioactivity of $\mathrm{P}-32$.

The samples were again given a wash

$$
\left(5 \% \mathrm{HF}+5 \% \mathrm{HNO}_{3}\right)
$$

to remove any accidental surface contamination. The radioactivity was measured in a low background (1 cpm) anti-coincidence beta-counter 14 days after removal from the pile. This ensures a complete decay of $\mathrm{Si}-31$ and $\mathrm{Au}-198$. For some wafers a severe wash in 3 parts conc. $\mathrm{HNO}_{3}+1$ part conc. $\mathrm{HF}$ to dissolve a part of the $\mathrm{Si}$ was also given, to remove also a substantial part of the gold present mostly at the surface [6]. Sufficient number of counts were obtained 


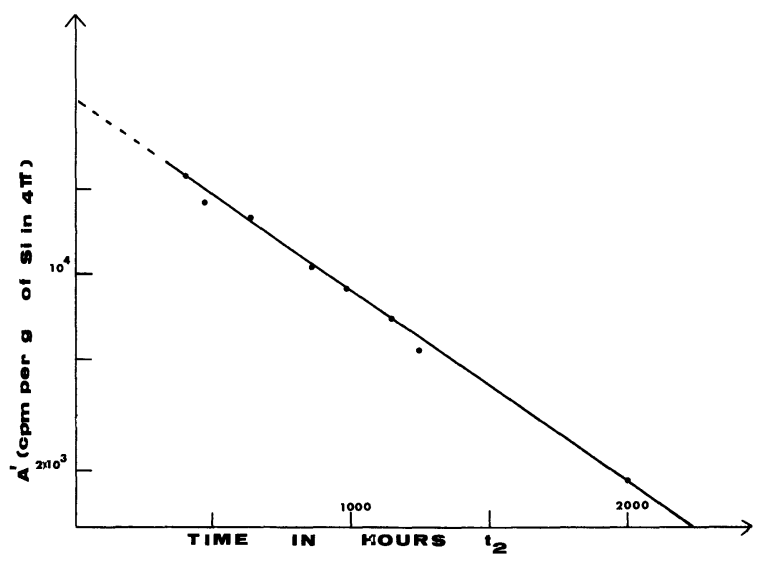

Fig. 2. - The experimentally obtained decay curve of a typical silicon crystal as a function of time.

in crystals of different masses ranging from 0.1 to $0.4 \mathrm{~g}$ in order to reduce the statistical error down to $2 \%$. The radioactive decay was then followed for 2 months (Fig. 2). The half-life time ranges from 13.8 to 19.6 days for the 6 samples where it is measured. Taking into account the statistical error of 2.2 days, one may conclude that there is good agreement with the half-life time for P-32 which is 14.3 days [7]. After a longer time, a small residual beta radioactivity is observed due to the traces of longer lived impurities such as $\mathrm{Sb}-124$. So, in a good approximation, the beta radioactivity measured between $t_{2}=2$ weeks and 2.5 months can be attributed solely to the P-32 atoms produced by transmutation of silicon after the double nuclear reaction.

As the samples are radioactive in the bulk, correction for self-absorption of the beta-rays is to be taken into account. The absorption coefficient for the quite energetic beta-rays emitted by P-32 $(1.71 \mathrm{MeV})$ and absorbed by silicon is measured. Because of the light mass of the silicon atoms, this correction is negligible for the very thin wafers under consideration $(300 \mathrm{~m})$.

Figure 2 shows a typical decay curve corresponding to P-32 activity. Equation (9) can thus be used to relate the residual beta-activity to the number of phosphorus atoms. However, the neutron crosssection $\sigma^{\prime}$ for the second nuclear reaction is needed. It can be determined from the present results and equation (9) where we use the cross-section for the first reaction $\sigma=0.102$ barn, as measured for the particular channel in TRITON reactor.
The counter efficiency is monitored for every counting with a standard beta-ray source. The average value is $R C=0.30$. One finally finds $\sigma^{\prime}=0.17$ barn with a standard mean deviation for the different samples of 0.02 barn. This value agrees well with the value of $0.19 \pm 0.01$ barn [7] obtained from irradiating pure phosphorus.

Therefore, equation (9) can be used to determine the mass $m^{\prime}$ of transmutated phosphorus atoms per gram of silicon. This is :

$$
\begin{aligned}
m^{\prime}=\frac{A^{\prime} M^{\prime}}{36 \sigma^{\prime} J \times R C} \times \\
\times \frac{t_{1} \exp \left(\lambda^{\prime} t_{2}\right)}{\left[t_{1}-\frac{1}{\lambda^{\prime}}\left\{1-\exp \left(-\lambda^{\prime} t_{1}\right)\right\}\right]} .
\end{aligned}
$$

Expressing as number of carriers, $C$, per $\mathrm{cm}^{3}$ of silicon after substituting for $M^{\prime}, \sigma^{\prime}$ and the specific mass of silicon :

$$
\begin{aligned}
C= & \frac{2.28 \times 10^{23}}{J} \times \\
& \times \frac{t_{1} \exp \left(\lambda^{\prime} t_{2}\right)}{\left[t_{1}-\frac{1}{\lambda^{\prime}}\left\{1-\exp \left(-\lambda^{\prime} t_{1}\right)\right\}\right]} \times \frac{A^{\prime}}{R C} .
\end{aligned}
$$

4. Conclusions. - When silicon is submitted to a thermal neutron flux for the purpose of doping, a second nuclear reaction occurs which produces radioactive phosphorus. We have measured the neutron cross-section for this reaction. We have then derived the equations which offer the following possibilities :

1) Equation (9) predicts the residual radioactivity of commercial samples at any time when the irradiation conditions are known.

2) Equation (11) relates this residual activity to the number of phosphorus atoms.

3) Equation (11) can be used to determine unknown irradiation conditions in commercial samples.

Acknowledgments. - One of us (V. K. A.) is thankful to the French Foreign Office for the award of a visiting Fellowship.

\section{References}

[1] Tanenbaum, M. and Mills, A. D., J. Electrochem. Soc. 108 (1961) 171

[2] Herrman, H. A. and Herzer, H., J. Electrochem. Soc. 122 (1975) 1568.

[3] SChNÖLleR, M., IEEE Trans. Electron Devices 21 (1974) 313.

[4] Platzöder, K. and Loch, K., IEEE Trans. Electron Devices 23 (1976) 805.
[5] Prussin, S. and Cleland, J. W., J. Electrochem. Soc. 125 (1978) 350.

[6] Bénière, F. and Agrawal, V. K., J. Physique Lett. 39 (1978) L-257.

[7] Handbook of Chemistry and Physics, 55th edition, edited by R. C. Weast (C.R.C. Press, Ohio, U.S.A.). 